\title{
Neuroimaging in Pediatric IMeurosurgery
}

\begin{tabular}{l|l|l} 
R.A. & Robert A. & Zimmerman \\
\hline
\end{tabular}

The Children's Hospital of Philadelphia, Pa., USA

This special issue of Pediatric Neurosurgery is devoted to recent contributions of pediatric neuro-radiology to pediatric neurosurgery. Neuroimaging has moved at a rapid pace during the decade of the 80s. We have all made the leap forward from CT to MR imaging. Ultrasound has also shown a similar steady progress. In this issue, the contributors have reviewed several highlights that these changes in neu-rodiagnosis have brought to neurosurgery. Dr. Richard Smith has reviewed intracranial infection, emphasizing the contributions of magnetic resonance imaging. Dr. James Barkovich has put into

perspective the current evaluation of hydrocephalus by neuroimaging. Dr. Otsubo and Dr. Chuang et al. have given us an insight into the utility of different imaging modalities in epileptic patients who are surgical candidates. I have had the opportunity of reviewing the use of MR in diagnosis of pediatric posterior fossa tumors, while Dr. Diane Babcock and associates have put intraopera-tive ultrasound into perspective. There is little question that we accept each new step forward and hold back our amazement that it will not end. In future issues of Pediatric Neurosurgery, we will bring you the future improvements. 